DOCUMENTOS 



\title{
Vieja y nueva comunicación política
}

\author{
Presentación \\ Ramón Adell Argilés \\ Profesor Titular de Sociología en la UNED \\ radell@poli.uned.es (ESPAÑA)
}

El texto que presentamos a continuación es la trascripción de la conferencia impartida por Iñigo Errejón en la Facultad de Ciencias Políticas y Sociología de la UNED, seis meses más tarde de la irrupción de Podemos en el Parlamento Europeo, (21-12-2014) como acto inaugural del Máster "Política y Democracia". Tras una breve presentación del catedrático de Ciencia Política Ramón Cotarelo, el Director de Estrategia y Campaña de Podemos inició su intervención mostrándose de entrada escéptico respecto al uso de la vieja comunicación política y el marketing, dada la reificación o "fetichización" de los dogmas teóricos al uso. Con un pleno de asistencia y con un sustancioso debate que, por razones de espacio, no aparece finalmente en esta publicación, resaltaré aquí, a modo de presentación, alguno de los aspectos centrales de su intervención; y más que un intento crítico de sus argumentos (que también Se Puede) aportaré algunas reflexiones explicativas al "fenómeno Podemos" en cuestión.

Para Errejón, el primerizo éxito político de Podemos no tiene receta secreta. Afirma que es una mezcla de riesgos y fortuna, de olfato y de osadía, de un proyecto nuevo frente al statu quo imperante. Modesta opinión, sin autofelicitaciones, ni autocríticas, ni grandes teorías, todo como por puro azar. En mi opinión, no es, como podría creerse, un proceso improvisado por tres antisistema locos o simplemente oportunistas (que no oportunos) sin preparación política. Como estudioso de los movimientos sociales y archivador de la memoria (de nuestra cultura política), tuve ocasión de conocer a Íñigo en 2007, recién licenciado. Muy buen olfato y bastante osado. Utópico, pero con convicciones. Me dio la impresión de que el joven se había leído ya, además de a San Marx, a Maquiavelo, Goebbels, Lenin y toda la retahíla insurreccional y sus posteriores variantes lights del marketing político, luego llamado Comunicación Política. Lecturas no siempre fáciles, pero también obligadas, supongo, para otros hitos de la comunicación: Sanchís, Feo, Santamaría, Guerra, Arriola, Moragas, etc., y de todos los jefes de campaña habidos. Versan sobre la ingeniería de la propaganda/publicidad política y su efecto en individuos y masas. Todo ello para mantener o conquistar el poder, según el caso. Lecturas legales, aunque no siempre bienintencionadas, y que ponen de manifiesto cómo la verdad y la mentira pueden desatar similares pasiones. Realidad versus percepción. Según Errejón, su tarea es "un proceso de trabajo intelectual, de 
análisis, para luego adaptarse a las situaciones concretas (crisis de régimen y cuestionar consensos)". Creíble. Por tanto, "el secreto de la pizza está en la masa", en las multitudes inteligentes, y en la hegemonía discursiva y, en consecuencia, política.

La clave de lo anterior estaría en el lenguaje y su propia construcción (Laraña), en conocer el lenguaje sencillo de la calle y descifrar el lenguaje alambicado del poder. El lenguaje "llega a ser un instrumento de control, incluso cuando no transmite órdenes sino información; cuando no exige obediencia sino elección, cuando no pide sumisión sino libertad", decía Herbert Marcuse. Se refiere Errejón al discurso mainstream, también llamado corriente o cultura principal. En el contexto de la "nueva política" (viejo término que recurrentemente aparece como nuevo), consistiría en irrumpir en el discurso general y ofrecer nuevas explicaciones de la realidad. Y ello pasa inevitablemente por lograr marcar la agenda setting y el debate a los rivales, desenmascarando el discurso del poder (lenguaje de la Administración Total, que diría Marcuse), al que de algún modo frámea constantemente. El contrapoder, contraprograma. Es una herramienta versátil y sin ideologías. Un ejemplo de ello sería el uso que hizo Esperanza Aguirre (ya en la oposición), durante el primer mes de Manuela Carmena como alcaldesa de Madrid, marcando temas, denuncias y falsos debates contra unos recién llegados con poca experiencia en "el poder" y la comunicación.

Cierto es que esa "osadía y olfato" a la que aludía en su intervención no hubieran tenido ningún futuro si no hubiera existido una oportunidad de contexto, una conectividad entre individuo, colectivos y, finalmente, voto. Un contexto de "mutación cultural" (Errejón) previo al llamado "efecto Podemos". Veamos algunos aspectos ilustrativos.

Con la bonanza económica, que en su momento engordó a las élites y permitió a millones de españoles/as ascender a la clase media, aunque fuera un espejismo temporal o ficticio, se instauraron también unos discursos y unos estilos. La pugilística lucha del individuo contra el individuo, contra todos. Las "excelencias" o "calidades" y demás términos de control y satisfacción atrajeron a instituciones, a mercados y a políticos hacia las prácticas de corrupción. La publicidad de bancos, pisos, coches, etc., se añadía al estilo de vida de nuestro soñado e impagable país.

Por su parte, en el año 2010, el sociólogo francés Alain Touraine afirmaba, que "la sociedad ya no existe, que se ha desarticulado, se ha desvertebrado". Se refería a las sociedades occidentales actuales, en un contexto general de la llamada posmodernidad. En nuestro país, y a tenor de lo que estamos viendo, podríamos afirmar que se ha roto el contrato social (estado del bienestar fruto de la transición) que implicaba consensos básicos, derechos, deberes y garantías individuales y colectivas. Otros efectos de la desvertebración social aludida, podrían incluir la creciente debilidad de las identificaciones partidistas tradicionales, el cinismo político, que lo público pasa a ser privado y viceversa, la secularización, y la utilización de referentes excluyentes como forma de contienda política. 
En nuestro país, con la crisis, la desvertebración ha sido especialmente dramática. Por el paso, en poco tiempo, de un bienestar insostenible a un insufrible malestar. Tiempos de "descomposición política, hastío y voluntad de cambio", según Errejón.

En una situación de alarma y emergencia social para gran parte de la población, irrumpe, como forma de supervivencia, "la creatividad social". Ésta consiste en crear redes vertebradoras para hacer lo que el Capital o el Estado no harán ya por nadie y menos por ti. Las gentes de El Común se estructuran, con su economía social, su apoyo mutuo y su fraternidad, sus valores, su tiempo y su organización. Con su presencia o sus votos, okupan además, de forma sistemática y planificada, espacios físicos, simbólicos y virtuales, abandonados previamente por las burbujas (inmobiliarias o institucionales), dejando a su paso en su descrédito (deuda y corrupción) espacios edificios, ayuntamientos, etc. En definitiva, Zonas de Autonomía Temporal en contextos excepcionales. Esto puede parecer hoy exagerado, pero en una crisis más duradera de lo que se anunció, o de lo que quisiéramos, esta tendencia no puede ser un modelo, pero sí una realidad. Por tanto, hablamos de fin de ciclo y de cambios futuros, y no sólo en España o Europa.

Tras el fuerte periodo de movilización del llamado 15-M o movimiento de los indignados (15-05-2011/22-03-2014), a día de hoy es innegable que se han producido en España importantes cambios. El paso de la indignación a la dignidad produce una nueva percepción de la participación democrática que se traslada a las urnas, como espacio privilegiado de la soberanía. Curiosamente, el efecto 15-M ("Dormíamos, despertamos. Lo llaman democracia y no lo es. De Norte a Sur, de Este a Oeste. Sí se puede...”) desaparece de las calles tras las marchas de la dignidad del 22-M, a la par que se produce el "triunfo sorpresa" de Podemos (1.245.000 votos y cinco escaños), un mes después, en las elecciones europeas del 2014. Desde entonces se aprecia un drástico descenso de las protestas en la calle, a excepción de la (única) demostración de fuerza de la convocatoria de Podemos por el cambio del 31 de enero de 2015, que reunió cerca de cien mil personas. Ello es un signo inequívoco de contención y moderación, que busca ampliar su base electoral, aun a costa de perder parte de sus activistas iniciales. Su vocación de partido acaparador (contrapoder hegemónico), y por tanto populista (ni de izquierda, ni de derecha, los de abajo contra la casta), tiene como fin ganar en las próximas elecciones generales. Desactivada la calle, el proceso no tiene ya vuelta atrás. El 15-M ya es historia, y la movilización que pudiera haber tras las elecciones podrá variar en función de sus resultados, pero será distinta a la protodemocracia asamblearia de los indignados. Su fulminante ascenso en los medios de comunicación y encuestas, y la alta capacidad de "representación" del 15-M han generado un enorme debate social.

El nombre de Podemos, nace del "sí se puede" del 15-M. Implica un nosotros y una acción volitiva de poder inmediato, en presente de indicativo. No le vale un dudoso "Pudiéremos", en futuro, ni se presenta como el Partido Demócrata Posibilista, fundado por Emilio Castelar (1879). Aparentemente, 
desde su aparición, la hoja de ruta del proyecto Podemos "de asalto a los cielos" (de la Moncloa) se va cumpliendo. Obviamente con zigzags, reajustes, desaceleraciones, etc., fruto de las experiencias electorales de Andalucía, y de las elecciones municipales y a comunidades autónomas. Entre las adversidades, destacan las acusaciones de corrupción por parte de algunos medios (caso Monedero, caso Errejón, Tania Sánchez), la participación en la nueva organización, a veces cuestionada desde dentro, su alejamiento del espíritu 15-M, o el contexto político de lo que suceda, por ejemplo, en Venezuela o en Grecia, generando un evidente desgaste del proyecto inicial. La ilusión se convierte en duda: burocracia y aparato crecen inevitablemente. Y en un futuro esa maquinaria se convertirá en competencias y cargos públicos. Son las leyes del juego electoral.

En su intervención, Íñigo Errejón se refiere a que parte del "éxito" se debe a que han sido sensibles a los problemas de la gente, a sus sufrimientos. Lo denomina la "politización de los dolores" (Jacques Rancière), que convierte el sufrimiento en práctica artística como praxis política y social, o el recurso a la expresión de sensaciones primigenias como placer o dolor. Eros y Tánatos. Es un recurso emotivo y sin duda eficaz. Gobiernos, asociaciones, colectivos, razas, religiones, clases sociales o géneros son víctimas. Otro asunto es el victimismo, como sobreexplotación del dolor, que genera perniciosos y desiguales conflictos en "las memorias históricas" de una colectividad, azuzando discursos de buenos y malos, víctimas y verdugos. Cada cual que imagine los ejemplos. En todo caso, la PAH (Plataforma de Afectados por la Hipoteca), y por extensión Podemos, dieron voz a los sin voz. Entre ellos, a los desahuciados anónimos que hicieron público y colectivo su drama personal (Outing). Esa sensibilidad que le faltó al PSOE, por ejemplo, pero también al Partido Popular; lo cual reconoció Floriano al afirmar, tras las europeas, que les "había faltado un poco de piel" para acercarse a la realidad.

Y aquí me referiré a uno de los actores que iniciaron (y que los yayoflautas concluyeron) el 15-M: la juventud. En el contexto actual, en que abundan más los "emperdedores" (Brieva), que los emprendedores, los/as jóvenes, aun siendo minoría numérica, son por definición el futuro. Tenemos una sociedad claramente envejecida y, a mi juicio, no se ha producido el clásico relevo generacional más o menos armonioso (superado el lógico choque generacional) de mayores a jóvenes. La herencia de valores, deuda, libros y demás objetos analógicos o materiales no es formateable. Estamos ante un "tapón generacional" similar a los que se destaparon también en los años 1975, 1982, 1997, etc. Las instituciones aparecen como gerontocracias incapaces de dar paso a las inquietudes de los más jóvenes. La reciente renovación de líderes políticos (e incluso de la Corona) nos muestra que algo está cambiando. Las nuevas tecnologías han acelerado el cambio de valores, de expectativas y de futuro de la sociedad y especialmente de la juventud. Y las instituciones van detrás... de los tiempos, ancladas como poco en el siglo pasado.

De mileuristas al paro a los minijobs o al extranjero. Al principio se les llamó los NiNis: "Ni trabajan, Ni estudian"; pero con el tiempo se amplían 
las críticas y muchos "Ni creen en esta democracia, Ni son antisistema". Paradójicamente, "Ni son violentos, Ni tienen miedo"; en fin, que "Ni ocupan Congresos, Ni dejan de rodearlos", "Ni aceptan los recortes, Ni los van a pagar". Al final no se contentan "Ni con Cánovas, Ni con Sagasta". Ningún adulto en sus cabales daba crédito a estás disfunciones, tras cuarenta años de democracia y bienestar.

Siguiendo el modelo desarrollista de la innovación y del cambio, Podemos (y salvando las distancias, en cierto modo, Ciudadanos) actúan como innovadores, lo cual nos muestra la demanda de nuevos estilos en la política. El contexto ha facilitado que los adoptantes precoces (indignados) y la mayoría precoz (afectados por la crisis) se hayan sumado rápidamente a sus discursos y esperanzas. La mayoría tardía (edades avanzadas) y los retardatarios (conservadores), con su legitimidad irreductible, mantendrán generacionalmente el bipartidismo. El tiempo dirá si este proceso es flor de un día, o si, como parece, se atisban cambios sociopolíticos de mayor calado: inciertos, pero no necesariamente traumáticos.

Tras esta breve introducción, leamos, pues, la transcripción de esta relevante conferencia. 


\title{
Vieja y nueva comunicación política
}

\author{
ÍñIGo ERREJón
}

Buenos días, gracias por la invitación. Gracias al máster Política y Democracia de la UNED, gracias a las autoridades académicas que me acompañan y gracias a Ramón Cotarelo por tomar la iniciativa de invitarme, y por su generosa presentación.

La aclaración inicial es que no sé si defraudo a algunos, pero no vengo aquí a hablar en nombre de ninguna formación política, ni vengo aquí a, digamos, contar una experiencia política, sino que vengo a proponer algunos elementos de discusión sobre qué cosa sea la comunicación política, algunos elementos fundamentales de la comunicación política y de porqué entiendo que es central en el momento en que vivimos y cómo se relaciona con algunas de las cosas que están sucediendo en el presente; esto es, discutir algunas ideas centrales a la luz de una experiencia concreta bien reciente, y que sigue marcando el devenir político de nuestro país.

La segunda advertencia, o matiz, sería que sin ánimo, o con no demasiado ánimo de ser provocador, yo soy normalmente muy escéptico con respecto a la comunicación política; por lo menos muy escéptico con respecto a la configuración de la comunicación política como un saber separado, propio, parcelado, del que se pueden aprender una serie de trucos y elementos que llevan a uno a adoptar fórmulas ganadoras.

Creo que, en lo sustancial, no hay nada muy distinto de la comunicación política que de la comprensión de los fenómenos políticos y de la práctica de la política, y creo que para hacer buena comunicación política, sea eso lo que sea, hay que hacer buena lectura de los momentos políticos, de los equilibrios de fuerzas que componen toda situación política, y hay que echarle un poquito de imaginación y hay que echarle valentía. Valentía para atreverse a leer, en los momentos políticos concretos, posibilidades que van más allá de lo que existe en ese momento. Posibilidades que, por supuesto, no pueden esperar a ser identificadas en los diagnósticos de la gran mayoría de los expertos y de las instituciones existentes, que fundamentalmente tienden a reificar y naturalizar el conjunto de las cosas que existen tal y como están. Y, por tanto, hay una parte siempre irreductible, que tiene que ver con el olfato y con la osadía, para no repetir lo ya existente.

Cuando, después de la noche del 25 de mayo de este año [2014], la noche 
de las elecciones europeas y del resultado de las europeas, empezó esa sacudida cualitativa -que me parece que los resultados de las europeas dieron al tablero político español-; digo cualitativa, porque cuantitativamente el resultado que obtuvo Podemos, que fue la novedad de aquella noche electoral, fue un resultado cuantitativamente modesto. Es verdad que si uno lo compara con los mimbres organizativos, los recurso económicos, el apoyo institucional o la propia duración de la iniciativa, pues es un resultado que no está nada mal. Pero por el otro lado, si uno lo compara con el resultado de descomposición política, de divorcio creciente entre representantes y representados, y de voluntad mayoritaria de cambio -o por lo menos de hartazgo y de hastío-, ese resultado es un resultado, en números, cuantitativamente muy modesto. Sin embargo, cualitativamente, fue suficiente para producir una serie de transformaciones aceleradas; transformaciones que, creo, se miden con herramientas, en este caso más cualitativas que cuantitativas; es decir, fundamentalmente con la necesidad de la práctica totalidad de actores políticos del escenario político español de parecer una cosa nueva después de la noche del 25 de mayo. Es decir, la necesidad de, sea en el formato más institucional del presidente del gobierno, para el cual la democracia española no tiene ningún problema hasta el 25 de mayo, y dos semanas después del 25 de mayo saca aceleradamente un plan de regeneración democrática; plan que luego uno podía discutir, digamos en términos de políticas públicas, cuánto de consistencia tiene; pero aquí no me voy a detener en eso.

Me interesa el dato de en qué medida era prácticamente obligatorio sacar algo como eso después de la pequeña sacudida del 25 de mayo. No digamos algunos cambios, sobre todo en términos de marketing político, vividos en el hasta ahora principal partido de la oposición y en fuerzas que ocupan un papel secundario o terciario. De alguna manera, incluso actores que seguían teniendo primacía electoral, primacía institucional, se encontraron, después de la noche del 25 de mayo, en una situación de necesidad de transmitir, no sólo imagen de cambios, sino de estar peleando en un terreno cultural a la defensiva; estar disputando en un terreno cultural marcado por palabras, por diagnósticos y por interpelaciones que les colocaban -hasta ahora, creo, hasta la fecha- a la defensiva. Y cuando, a partir del día 25 de mayo, los medios de comunicación empezaban a llamar, con esta cosa, lamento decirlo, muy periodística de "dígame usted exactamente cuál es el ingrediente secreto de esta fórmula que nadie vio venir, qué pasó aquí para que de repente se produjera una especie de tormenta perfecta que ninguno vimos venir, que no sabíamos que existían hasta ayer"; hay profesionales de los medios de comunicación que reconocían que algunos de los miembros del gabinete, del gobierno, la noche electoral preguntaron quiénes eran estos de Podemos que han sacado cinco eurodiputados. "Así que, díganos usted" -y a mí me pasaba mucho en calidad de haber sido el director de la campaña electoral-, "díganos usted exactamente cuántas gotas de cuántos elementos han combinado y cuál ha sido ese elemento secreto que se nos ha escapado y que ha permitido que se genere un fenómeno de esta magnitud". 
Y yo creo que esa visión es incorrecta. Y fijaos que en realidad, seguramente sería un fraude, pero sería mucho más cómodo decir: "Bueno, pues voy a explicar cuál ha sido la fórmula exacta, y además la tengo yo acuñada y la tengo registrada". Pero creo que eso no sería una buena explicación de la cuestión. Por una parte, no sería una buena explicación de la cuestión porque sigue siendo una lógica que creo que no sabe leer los acontecimientos presentes, porque sigue siendo una lógica muy de cuño de renovación de élites; es decir, los héroes siguen siendo héroes individuales. Si se ha producido un fenómeno que nadie ha visto venir, y que para alguien merece respeto, admiración -le merezca la opinión que le merezca ideológicamente, pero le merece como ser destacado-, ha tenido que ser por un conjunto de grandezas individuales que no equivalen, en ningún caso, a una creación colectiva. Como en las películas norteamericanas, cuando el héroe se cruza con una manifestación, y la manifestación siempre es una especie de, no sé, de paseo de ganado desprovisto de cabeza. Siempre que aparece una manifestación en una película norteamericana es un estorbo de gente que hay que apartar, porque el que va a solucionar la cuestión es siempre uno, individualmente, y tiene entre medias gente que lo estorba. Y creo que, con esa lectura, no seríamos capaces de percibir o de diagnosticar hasta qué punto se han producido, por lo menos en los últimos tres años, cambios culturales centrales que fueron capaces de abrir un espacio político que hasta entonces no estaba disponible en España. Cambios culturales entendidos fundamentalmente como un cambio en las percepciones de las cosas que nos suceden y en las explicaciones disponibles de lo qué nos está sucediendo, por qué nos sucede, quién es responsable de que nos suceda y si las cosas podrían ser de otra forma.

En otras palabras, creo que las élites tradicionales en España han vivido primero un proceso de retroceso cultural, o de deslegitimación cultural, y ahora están viviendo $-\mathrm{o}$ parece que podrían vivir- un proceso de retroceso político; pero ha venido primero, y es fundamental el diagnóstico de por qué mutaron las gafas, por qué cambiaron las gafas con las que veíamos la realidad de lo que nos afectaba; y qué elementos contribuyeron a que esa realidad cambiase.

Y el segundo aspecto, en el que no me detendré más, pero que hay que anotar por honestidad, tiene más que ver con una suma de asumir riesgos y de fortuna. Que esto queda muy mal decirlo siempre en los análisis políticos, porque parece que uno tiene que demostrar que lo tenía todo escrito en una libreta... Pero nunca es verdad. En la realidad hay una parte fundamental de atreverse, de lanzarse; y, cuando uno se lanza, asume que todo el mundo tenga escrito todas las razones por las que estaba errado, y todas las razones por las que se había equivocado. No digamos con nuestra experiencia: desde que Podemos se lanza, hay una legión de expertos, a derecha e izquierda, que tienen clarísimo por qué eso no va a funcionar. Y lo tienen, además, firmado desde el primer día. Y lo tienen como para sacarlo al día después, y para decirle el 26: "Ves, esto ya te lo dije, que esto no iba a funcionar". 
Y ahí hay que reconocer que la política es un deporte de riesgo y que, para asumirlo, hay que decir que, sobre todo, en la era de las redes sociales, me parece que todo el mundo tenemos una opinión y además la podemos expresar en párrafos en nuestro Facebook, y además no hay ninguna manera de medir si alguna es más correcta que otra: todos tenemos muchísima razón. Pero, cuando se trata de poner alguna de esas razones, o alguna de esas intuiciones o de hipótesis a trabajar, hay que arriesgarse, y hay que mancharse, y hay que remangarse, y poner a jugar, o poner encima de la mesa, elementos que, pues no están garantizados, y sobre los que no hay certidumbre. Primero, porque uno nunca puede controlar todas las variables, y, segundo, porque hay algunas que son siempre variables indeterminadas, que tienen que ver con una suerte de hechos, no voy a decir fortuitos, pero sí que se escapan a la capacidad de control de quien lanza una iniciativa: cómo va a reaccionar el adversario, en qué medida se van a suceder una serie de hechos en la actualidad, que son imprevisibles, que van a ayudar o van a dificultar... Y, por tanto, son un conjunto de elementos que hacen imposible, o que convertirían en fraude que cualquiera dijera: "Bueno, pues aquí hay una receta de éxito".

Y hay muchos manuales de marketing político y de comunicación política, pero yo tengo que decir que no usé ninguno para la campaña electoral. Esto no significa que no los haya leído, pero esto significa que mi opinión no va por ahí. Pero, yo vengo de trabajar en la universidad, y esto no tiene que ver con una suerte de apología de la práctica por encima de la reflexión. En absoluto. Sin ideas y sin un marco conceptual lo que hacemos es acumular experiencias que se caducan al día siguiente. Es fundamental el trabajo intelectual, el trabajo conceptual. Cualquiera que nos conozca un poco -[volviéndose hacia Cotarelo] Ramón nos conoce desde las primeras fechorías- sabe que en Podemos hay una hipótesis intelectual largamente larvada, largamente discutida, muy escrita... Lo que pasa es que cuando los medios de comunicación preguntan: "Y esto, ¿de dónde ha salido?", les decimos: "Hombre, lo que pasa es que no nos leía nadie", como era a lo mejor natural, pero uno puede hacer hemeroteca y revisión de bibliografía académica y ver que, efectivamente, hay todo un trabajo de discusión, de elaboración, de análisis y de prueba de hipótesis que ahí está; un trabajo muy modesto que de repente se encuentra con unas condiciones más o menos favorables.

Así que, en absoluto, supone ninguna descalificación del trabajo intelectual, del trabajo de análisis, de discusión, de lectura previo. En absoluto. Pero sí que significa que ese trabajo para que funcione, creo que hay que hacer dos cosas. Por una parte, hay que aplicarlo -y esto es una perogrullada- a una situación concreta, hay que ser capaces de leer la situación concreta, y leerla muchas veces y, en los momentos de cambio, leerla a contrapelo; es leerla cuando hablar de crisis de régimen era ser un marciano en este país; es leerla cuando hablar del agotamiento de algunos de los marcos institucionales y de los consensos 
salidos del pacto político de la transición equivalía a una suerte de poner en duda toda nuestra tradición política y querer cargarse los fundamentos del sistema democrático. Es decir, que tiene que ver a veces, en los momentos sobre todo de crisis..., no sé si es demasiado aventurado decirlo, de crisis orgánica, en la cual el conjunto de lo existente no es capaz de ofrecer ni soluciones institucionales ni una integración cultural y simbólica de los anhelos de una buena parte de la población al orden constituido. Cuando se da una situación así, pensar es siempre pensar a contrapelo, es siempre pensar frente a lo que dicen los expertos, es siempre pensar frente a lo que están diciendo los medios de comunicación. Pero no frente en el sentido de "opuesto a", o para chocar; es pensar, con razones y con categorías, que el conjunto de lo establecido no va a ponerse a disposición de quienes quieran transformar lo existente. Así que es pensar asumiendo riesgos. Es pensar asumiendo que es más difícil que te den las becas. Es pensar asumiendo que va a ser más difícil que te publiquen en las revistas académicas. Es pensar asumiendo que te va a tocar defender discusiones un poco más incómodas que si repites el discurso meistream. El discurso meistream no tiene ningún problema, no es una suerte de voluntad de ser iconoclasta, por ser siempre iconoclasta; no, no. Se trata de intentar leer en la situación concreta: “Nos valen los instrumento que tenemos para pensar lo que existe, y valen a la vez los canales institucionales, los consensos existentes, las representaciones de lo existente? ¿Nos valen para pensar lo que se está moviendo por debajo, en un nivel, digamos, magmático de la sociedad civil?". Bueno, si nos vale, magnífico. Si no nos valen, hay que atreverse a pensar en las grietas, a pensar en los lugares que no son tan confortables.

Así que, por una parte, análisis; un análisis que, en mi opinión, tiene que ser un análisis siempre del conflicto. Incluso en los casos de sociedades más institucionalizadas, más estables y con más alto grado de consenso, ese consenso y esas instituciones son siempre el resultado de un equilibrio pactado, con procedimientos pactados, entre diferentes grupos y diferentes intereses. Incluso aunque las instituciones tengan siempre, por su naturaleza, la obligación de producir la imagen de congelación, de sedimentación, casi de eternidad y de universalidad, son siempre un resultado contingente -que podría cambiar: no siempre ha estado y no estará para siempre, aunque todas digan que lo estarán- de un determinado acuerdo y un determinado equilibrio entre grupos. Y, por tanto, pensar desde el conflicto -y aquí a mí me sirve siempre mucho la politóloga Chantal Mouffe: pensar desde el conflicto, que no es pensar para el conflicto, sino pensar que toda situación siempre es un acuerdo determinado, congelado en un momento dado, entre diferentes grupos y diferentes interesesayuda a ser capaz de diagnosticar en qué medida esos acuerdos, esos marcos, esas instituciones contienen o no contienen una parte de ese conflicto siempre latente en lo social.

¿Son capaces o no son capaces las instituciones de integrar en buena medida una parte de las quejas de los que obedecen, de tal manera que los que obedecen 
encuentren legítimas, y de interés general, y buenas para todos las razones de los que mandan? ¿En qué medida vivimos en un momento de estabilidad en el cual, más allá del recurso, digamos, más desnudamente coercitivo, las razones de los que dirigen son las razones y la forma de ver el mundo naturalizada del conjunto de los sectores subalternos? Si eso pasa, estamos claramente en una situación, digamos hegemónica y de inestabilidad, en la que podemos pensar es en reajustes o reacomodos, en los equilibrios en la dirección del conjunto social. Si eso no sucede, lo que estamos es ante una situación, en la cual hay una brecha, hay una grieta abierta, por la cual quienes mandan son capaces de mandar, son capaces de conducir una comunidad política, pero no son capaces de hacerlo suscitando el consentimiento amplio, o integrando con sus razones y con sus explicaciones del mundo a una buena parte de quienes tienen un rol subordinado, de quienes, digamos, obedecen un poco más de lo que mandan. Es decir, de la mayor parte de nosotros.

Si eso sucede, hay que diagnosticar, me parece, cuáles son las razones de que eso sea así; cuáles son esas grietas que se producen, por las cuales una parte de lo existente no contiene los anhelos, las expectativas o las quejas de una parte sustancial -en nuestro caso, me parece que mayoritaria- de una sociedad. Y al hacerlo me parece que nos adentramos siempre en una visión de la política como una lucha por el sentido que le damos a las cosas, en la que ninguna de las explicaciones que le damos a ningún hecho de lo social puede darse por anclada ni puede darse por descontada, sino que son siempre el resultado de una lucha -una lucha, casi siempre, afortunadamente pacífica- por fabricar el sentido que le damos a las cosas y las posiciones que toman las cosas.

Y ahí a mí me parece que, a partir del 15 de mayo de 2011, hubo una quiebra en el sentido instituido en España; hubo una pequeña grieta, y esa grieta no tuvo que ver con el conjunto de la gente que se movilizó, sino con la capacidad de poner en marcha explicaciones de lo existente diferentes a la casi explicación única que existía hasta entonces. Me parece que a partir del 15 de mayo de 2011 se abre un proceso de pequeña transformación cultural que permite la apertura, que permite imaginar espacios políticos diferentes, que permite lanzar iniciativas políticas que antes parecían condenadas a moverse en los márgenes de lo existente, en posiciones extraordinariamente minoritarias. Por qué creo que sucede eso. ¿Cuáles creo que son algunas de esas transformaciones?

La primera diría que es una transformación que tiene mucho que ver $-\mathrm{y}$ aquí sigo fundamentalmente a Ransier-, una transformación que tiene mucho que ver con esa pulsión que está siempre en el corazón de la democracia, que es la politización de dolores que hasta entonces se vivían de forma no política; es decir, como dolores, culpas o problemáticas privadas, o problemáticas que no tenían una explicación que se derivaba de la ordenación que tenía la sociedad. Eran problemas naturales que siempre habían estado, que siempre iban a estar, o que no tenían responsables. 
Me parece que el 15-M lo pone encima de la mesa, y siempre uso algunos ejemplos parecidos... Os acordáis de que antes de el 15-M era muy frecuente ver a humoristas-y en series de televisión- hacer parodias sobre una generación que, teniéndolo todo, bueno, era como particularmente poco, no sé, poco emprendedora, poco hábil, y os acordáis de todas estas bromas sobre la generación de los ninis, que era casi como una especie de culpa y de carga generacional. Insisto, más allá de lo cierto que esto fuera, lo real es que hoy sería extraordinariamente difícil que un humorista hiciera un sketch similar. Sería muy difícil que hoy un humorista saliera a hacer una broma diciendo que los jóvenes españoles no se van de casa de su padres, los que más tarde se van en toda Europa porque, no sé, porque son meridionales y le tienen mucho apego a sus familias. O que alguien hiciera una broma sobre los jóvenes españoles que se van a conocer mundo en Londres. Pero estas bromas sí se hacían y, insisto, no lo digo para hacer combate político, estoy intentando poner elementos para el análisis. Se hacían y dejaron de poder hacerse. ¿Qué sucedió entre medias? Entre medias sucedió un cambio en la percepción de algunos fenómenos que ayer se vivían como fenómenos despolitizados y que hoy empiezan a vivirse como fenómenos políticos, que tienen responsables concretos, tienen culpables, tienen víctimas concretas. No es una carga que nos sucede a todos. Tienen víctimas concretas, tienen una explicación y podrían tener una solución alternativa.

Otro ejemplo seguramente central sería el drama de los desahucios en España. El drama de los desahucios ha pasado a ser de una carga individual, que uno sufría incluso, a veces, en privado; no lo decía, "me da vergüenza haber perdido mi casa, porque es casi una carga individual, no he sido capaz de hacer frente a la carga hipotecaria del banco. Incluso me echan de mi casa y me voy en silencio, no se lo digo a mis amigos o a mis familiares, que he perdido la casa". Quienes trabajan en la Plataforma de Afectados por la Hipoteca saben que estos son casos que se daban mucho; que por desgracia, en menor medida, todavía se dan. Y de repente hay un momento en el que los desahucios dejan de ser una vergüenza individual y empiezan a ser una vergüenza colectiva; dejan de ser una falla individual -te han echado de tu cas y tienes la culpa tú- y empiezan a ser una impugnación a cómo hemos ordenado las leyes y la convivencia de forma tal que sea posible que haya una alternativa. Lo digo en forma breve, pero que las familias sean echadas de sus casas, mantengan a la vez la deuda, y a la vez, en algunos casos, sean incluso de bancos que hemos rescatado entre todos, con banqueros que tienen sueldos de los más altos de Europa...

Cuando sucede esto, lo que está sucediendo entre medias es una transformación de la forma en la que vemos una buena parte de los problemas que nos sucedían, una lucha por el sentido, en la cual el sentido que le damos a las cosas, la explicación que le damos a las cosas, varía. Y al variar permite una interpretación de signo diferente, incluso una ordenación de tipo diferente de las posiciones políticas en el escenario político español. Una ordenación que, 
tendencialmente, ya en el 15-M, colapsa, impugna una parte de la diferenciación interna en el sistema de partidos, dice: "No, no, la diferencia fundamental no es que ustedes, unos sean de izquierdas y otros sean de derechas; la diferencia fundamental está entre, digamos, una mayoría que no se siente representada y una minoría que detenta los lugares del poder, y lo detenta no en beneficio de las mayorías". Sea o no cierta, comparta uno o no esta afirmación, es muy legítimo que uno diga: "No, no, eso es una...". Hay incluso una cosa generacional, o sea que hay mucha gente que dice: "Esto es una tontería, esto es lo que diría Le Pen, esto no tiene ningún sentido", Esto es legítimo decirlo. Bueno, según, ¿no?, con matices en el tono. Pero esto es muy legítimo pensarlo. Pero lo que ya no se puede hacer es impugnar que esa explicación es claramente una explicación que viene a satisfacer y a responder a una percepción social, si no mayoritaria, por lo menos muy amplia.

Y con esto entronco con la segunda cuestión que decía era fundamental, un diagnóstico de lo que sucede. ¿Son las explicaciones de los que mandan suficientes para integrar las quejas, las aspiraciones de la mayor parte de la sociedad? ¿O no? Si no lo son, ¿por qué no lo son? Y si uno diagnostica que no lo son, entonces hay quejas, sentidos, palabras incluso -nosotros somos artesanos que fundamentalmente trabajamos con palabras-, palabras fundamentales sobre las cuales se está produciendo una lucha, una disputa para darles un significado o darles otro. Palabras cuyo significado no es tan claro, no está dado de por sí, y sobre las cuales se está produciendo una batalla, como si fueran colinas por tomar por uno u otro. (Afortunadamente, utilizo metáfora bélicas sin ninguna intención belicista, sino por deformación de algunos de los autores con los que trabajo). Colinas cuya toma corresponde con una cierta capacidad de instituir explicaciones de lo general, de dar explicaciones a lo general que sean capaces de construir una mayoría en un sentido o en otro.

Y el segundo elemento central aquí es el elemento de la traducción. Y la traducción tiene que ver siempre con una simplificación. Cuidado, porque aquí es muy fácil que uno diga: es relativamente sencillo que haya quien interprete que la simplificación es una suerte de perversión de la complejidad con la que nosotros trabajamos. En la realidad nunca hay traducción de los diagnósticos a la intervención política sin simplificación. Y una simplificación no es una especie de renuncia a la complejidad y a las múltiples aristas que tienen los problemas, en absoluto. Es un reconocimiento de que hay dos lógicas: hay una lógica del análisis y hay una lógica de la intervención. Y hay complejidades centrales para la lógica del análisis, que luego deben ser traducidas para la lógica de la intervención política. (Pero esto no es nada original; esto, si me apuráis, me parece que es una lectura no demasiado sofisticada de Weber). Y por tanto, creo que tenemos que reconocer que toda práctica política es una práctica que traduce y, al traducir, tiene siempre que fabricar explicaciones simplificadas de lo existente, y que esas explicaciones simplificadas son las que son capaces de producir reequilibrios en las posiciones que la gente adopta sobre los problemas. 
Es más, son las que tienen la capacidad de hacer una cosa que, para mí, es central, que es dibujar cuál es la frontera fundamental que delinea las posiciones, las tomas de posición, con respecto a lo que nos pasa en una comunidad política de la gente. Son los que son capaces de dibujar cuál es el elemento fundamental que va a dirimir el ellos y el nosotros; que va a dirimir cuál es la razón que nos hace tomar bando y cuáles son los bandos.

Diría que, en ese sentido, la política es una pelea en la que lo fundamental ocurre antes.. ¿Habéis visto la película Braveheart? Pues es una pelea en la que lo fundamental no ocurre cuando chocan los dos ejércitos ya compuestos, sino que ocurre antes. Ocurre en la construcción de esos bandos. Y quien es capaz de haber construido los bandos definiendo el terreno de juego, el lenguaje y los motivos, las razones en torno a las cuales se constituyen los bandos, ha empezado la batalla seguramente con el cincuenta y uno por ciento ganado. O con el cincuenta, diría, porque luego hay muchas cosas que están indeterminadas. Pero me parece importante quedarse con la idea de una batalla en la cual quien fija los términos y las condiciones de la contienda empieza ganando por lo menos la mitad de la misma. Y eso tiene que ver siempre con esta traducción, o esta simplificación de la que hablaba.

La simplificación, es decir, la reunión de un conjunto de elementos dispersos que están en el análisis, que sean capaces de producir un relato, una explicación coherente, sencilla, accesible y de fácil transmisión, es un momento siempre central de la disputa política. Y no hay nadie, absolutamente nadie, que no lo haga. Eso siempre tiene que ver con una capacidad de fabricar, y cuando digo fabricar no me refiero a "inventar en alquimia de la nada", sino con las materias primas disponibles; y las materias primas disponibles son siempre los contenidos sociales de la vida cotidiana, los dolores, las preocupaciones de la gente, las políticas públicas existentes, la capacidad de reacción o de adaptación de las instituciones... Pero la capacidad de-con esas materia primas- fabricar metáforas, símbolos, palabras que sean capaces de forma extraordinariamente gráfica, de resumir qué está pasando en un momento dado en una situación concreta.

No es la única, pero seguramente lo que más ayuda a esta explicación es que yo pronuncie la palabra casta. La palabra casta, que es de larga utilización en la ciencia política, en este caso no tiene valor por su capacidad explicativa. Uno, si lo tuviera que explicar en un paper, seguramente tendría que hacer una explicación más larga, más llena de matices y más compleja. Eso no significa que sea verdad o mentira; diría fundamentalmente que, sobre todo en la lucha discursiva, los elementos de verdad o mentira nos ayuda menos para comprender qué pasa, para comprender qué hacemos. No porque no existan; no es una suerte de postura cínica según la cual no existen. Esos son fundamentales para la toma de posición como ciudadano, con qué se compromete uno, qué cree que existe, qué cree que no, qué cree que es válido y qué cree que no. Pero, en lo 
fundamental, tenemos que aprender que estamos trabajando con materiales en los cuales una explicación política es cierta si produce efectos tales como si fuera cierta; es decir, si es capaz de producir consenso en torno a una identificación.

Cuando alguien pone en marcha la metáfora: "Los estados" -una cosa como típicamente neoliberal-, "los estados son como familias que no pueden gastar lo que no tienen". Bueno, pues esto no resiste el menor análisis en una revista científica de economía, por ejemplo, porque dices: "Hombre, sí, salvo que las familias no tienen bancos centrales, por ejemplo". Pero da igual, porque el objetivo de esta metáfora no es ser capaz de describir en toda su complejidad todo lo que está sucediendo, sino producir una explicación resumida de lo que sucede, que sea muy fácil de transmitir, que sea evidente, que no necesite ser discutida, que circule a toda velocidad, siendo inmediatamente evidente, y reduciendo el conjunto de una discusión muy compleja a unos términos evidentemente favorables para quien la ha puesto en circulación. En este caso, bueno, que lo fundamental no es aumentar los ingresos, sino reducir los gastos. Pero si tú explicas lo contrario, bueno, pues es posible que tengas una parte de éxito bastante menor. Y, por tanto, es posible que seas menos capaz de instaurar estas gafas con las que la mayor parte de nosotros vemos el conjunto de lo que pasa. Pero lo importante ahí -que es lo fundamental, me parece, en una relación hegemónica- es que no sólo lo vean los que están de acuerdo contigo; es que, incluso, quienes no están de acuerdo contigo estén obligados a pensar con tus categorías, en tus términos y a discutirte. Es que tienen que salir a decir: "No, no, yo no soy casta". O que otros tienen que salir a decir: "Bueno, sí, somos una familia, pero es verdad que...". Es decir, que tú has sido capaz de construir, con determinadas explicaciones que has dado, con un relato determinado de lo real, has sido capaz de construir un marco en el que incluso tus adversarios te tienen que contestar.

Siempre cito la misma anécdota, que me parece reveladora. En una entrevista que le hacen a Margaret Thatcher, ya cuando ha acabado su mandato, le preguntan cuál es el logro político del que se siente más orgullosa. Y dice: "Yo, Tony Blair y la tercera vía". Claro, tiene dos partes la respuesta. Tiene una parte de mala leche y tiene una parte de descripción de una relación hegemónica: he construido una forma de interpretar lo que sucede, una narrativa, una explicación del mundo -en mi sociedad, claro, en Gran Bretaña-, que incluso mis adversarios tienen que utilizar mis categorías, hablar como yo, e incluso inscribirse en un mismo horizonte de sentido para desafiarme. Es decir, que eventualmente claro que me podrán ganar, pero cuando hayan ganado ya no son los de antes: me han ganado a condición de ser un poco yo, a condición de parecerse un poco a mí.

Pongo otro ejemplo parecido - para que mañana alguien lo saque-, que es la reacción de las nuevas derechas frente a los gobiernos progresistas en América Latina. Voy a poner el ejemplo que más conozco, que es sobre el 
que hice la tesis doctoral. En Bolivia, la oposición ha pasado en una década de decir (y yo esto lo sé porque a mí me lo dijo un constituyente, haciéndole una entrevista para mi tesis doctoral): "Antes vivíamos todos los bolivianos unidos, y ahora este gobierno nos quiere dividir, entre los que somos indios y los que no son indios" -que es siempre una cosa de los privilegiados: quienes dicen "hay una cosa que me duele" están introduciendo conflicto en la comunidad política-, "antes estábamos bien, antes éramos una familia unida, pero ustedes han introducido una dimensión... y aquí se pueden poner muchas a lo largo de la historia... "una dimensión que politiza un dolor y que por tanto siempre dibuja una división". En muy pocos años han pasado de decir: "Resulta que este gobierno nos quiere dividir por las razas, es un gobierno racista porque introduce la raza como un elemento de división", a asumir que ninguna candidatura es viable si no lleva un indígena en los tres primeros puestos. $\mathrm{O}$, han pasado de decir: "La recuperación para el estado de los contratos y de los carburíferos, del gas, va a ser un fuente de corrupción", a discutir la forma en la que se produce la recuperación de los contratos. Ni uno solo de los candidatos que disputaban las elecciones -que fueron hace un mes-, del pasado 12 de octubre en Bolivia, ni uno solo de los candidatos, incluso desdiciéndose de lo que habían hecho en el pasado, era capaz de competir con el que todavía era presidente y que aspiraba a la reelección, Evo Morales, refutando alguno de los elementos centrales de lo que constituía el relato fundamental del MAS en Bolivia. Incluso sus más acérrimos adversarios, no se podían permitir hablar de volver a privatizar los recursos del gas, no se podían permitir hablar de que Bolivia es un país mestizo en el que no hay diferencias y en el que introducir lo indígena es introducir la división(introducir lo indígena como indígena; no es que no hubiera indígenas antes en los puestos políticos en Bolivia. Llegó a haber un vicepresidente que lo era). Digo introducir lo indígena en tanto que indígena, es decir, "estoy aquí en tanto que representante de..".

¿Eso qué significa? Eso significa que se ha producido una mutación cultural de tal calado, a menudo más difusa, pero más profunda que los cambios institucionales, que va a modificar las pautas de relación, por las cuales incluso el adversario que gane $-y$, eventualmente, en democracia, siempre hay un adversario que te gana-, tendrá que haber ganado "habiendo pagado el precio" de haberse parecido mucho a ti, o de haber heredado una buena parte de tus contenidos. Esto, en mi opinión, nos habla de hasta qué punto, más allá de las competiciones electorales, más allá de las competiciones institucionales, hay un elemento central en la política -no en la comunicación política: en la política-, un elemento fundamental de lucha por producir el sentido, por producir las explicaciones de lo que sucede en una sociedad dada, a qué se deben nuestros problemas, quién los provoca, quién los sufre, cuáles son las respuesta disponibles y en qué medida esas respuestas son útiles, no son útiles, satisfacen los intereses de todos o de algunos. Es siempre, en definitiva, una lucha por la construcción del interés general; que es siempre una lucha que tiene una parte relegada y una parte que está en posiciones dirigentes; una parte que es capaz de 
encarnar en torno a sí el universal y una parte que forma parte de ese acuerdo en otra forma..., siempre con una posición subalterna, o en una posición asimétrica.

Entender que esto es una relación que está en continuo movimiento y que tiene que ver con una disputa cultural, con una disputa intelectual que está siempre abierta, es lo fundamental de la posibilidad de intervenir para abrir en escenarios que parecen cerrados - del escenario como del impasse: cómo es posible que si estamos todos tan hartos no cambie nada-, en escenarios que parecían cerrados, que parecían condenados a la naturalización de un orden que no podía ser impugnado; ver como en ésos escenarios puede que se estén abriendo grietas para poner en marcha explicaciones diferentes que sean capaces de alterar los equilibrios de fuerza en favor de sectores sociales que sientan legítimamente o no, esto ya depende de la toma de posición de cada uno- que sus intereses no están siendo representados, que sus anhelos no encuentran un cauce o una promesa de futuro adecuada en el orden institucional dado. Me parece que esa es una buena parte del marco en el que pensar la comunicación política como una lucha discursiva, como una lucha por construir significados, y en algunos casos por construir significados que no están dados o que parece que no están escritos, parecen a veces incluso impensables.

Ramón [Cotarelo] me había dicho, justo cuando entrábamos: "aterriza y vete a lo concreto". Temo no haberlo hecho, pero es verdad que me paso los días últimamente yendo a lo concreto y tenía un poco de ganas de discutir "en serio". En todo caso, espero que las preguntas y la discusión puedan servir para aterrizar algunos elementos, si es que no los he aterrizado, o para concretar algunas cuestiones si es que han quedado dibujadas en términos, digamos, demasiado abstractos. Muchas gracias.

Se abre el turno de preguntas. 
